\title{
Monumento ao Cristo Redentor, em Itaporanga - PB: uma análise acerca da necessidade de preservação do patrimônio histórico e cultural nacional
}

\author{
Monument to Christ the Redeemer, in Itaporanga - PB: an analysis of the need to preserve the \\ national historical and cultural heritage \\ Monumento al Cristo Redentor, en Itaporanga - PB: un análisis de la necesidad de preservar el \\ patrimonio histórico y cultural nacional
}

\section{Resumo}

O trabalho em questão tem por objetivo realizar uma abordagem acerca do patrimônio histórico e cultural, de forma genérica, passando, posteriormente, à análise do Monumento ao Cristo Redentor, situado na cidade de Itaporanga, na Paraíba. Nessa perspectiva, este estudo, por meio da pesquisa exploratória, de natureza qualitativa, método dedutivo, coleta de dados bibliográfico e documental, procedeu-se de modo a realizar uma análise acerca da importância dos patrimônios históricos e culturais nacionais, associando-a à necessidade de preservação dos mesmos, através da atuação da administração pública em âmbito nacional, estadual e municipal. Nesse sentido, buscou-se ressaltar as origens e histórias que norteiam o referido patrimônio local, as quais justificam a necessidade de preservação, sendo esta uma atribuição da União, do Estado e do Município, com a colaboração da sociedade. Finalmente, diante da problemática exposta, buscou-se, embasado nos ditames que regem a Carta Constitucional, elucidar a necessidade da Administração Pública, pautada na defesa da cultura e história nacional, buscar atuar diante desse seu dever de proteção do patrimônio histórico-cultural nacional.

Palavras-chave: Patrimônio; Preservação; Administração pública.

\begin{abstract}
The work in question aims to carry out an approach about the historical and cultural heritage, in a generic way, passing, later, to the analysis of the Monument to Christ the Redeemer, located in the city of Itaporanga, in Paraíba. In this perspective, this study, through exploratory research, of qualitative nature, deductive method, collection of bibliographic and documentary data, proceeded in order to carry out an analysis about the importance of national historical and cultural heritage, associating it to the need their preservation, through the performance of public administration at national, state and municipal levels. In this sense, we sought to highlight the origins and histories that guide the referred local heritage, which justify the need for preservation, which is an attribution of the Union, the State and the Municipality, with the collaboration of society. Finally, in view of the exposed problem, it was sought, based on the dictates that govern the Constitutional Charter, to elucidate the need for Public Administration, based on the defense of culture and national history, to seek to act in face of this duty to protect the national historical-cultural heritage.
\end{abstract}


Keywords: Heritage; Preservation; Public administration.

\section{Resumen}

El trabajo en cuestión tiene como objetivo hacer un acercamiento general al patrimonio histórico y cultural, pasando, posteriormente, al análisis del Monumento al Cristo Redentor, ubicado en la ciudad de Itaporanga, en Paraíba. En esta perspectiva, se procedió a este estudio, a través de una investigación exploratoria, de carácter cualitativo, método deductivo, recolección de datos bibliográficos y documentales, con el fin de realizar un análisis sobre la importancia del patrimonio histórico y cultural nacional, asociándolo a la necesidad de su conservación. , a través del desempeño de la administración pública a nivel nacional, estatal y municipal. En este sentido, se buscó resaltar los orígenes e historias que orientan el referido patrimonio local, que justifican la necesidad de preservación, que es una atribución de la Unión, el Estado y el Municipio, con la colaboración de la sociedad. Finalmente, ante la problemática expuesta, se buscó, con base en los dictados que rigen la Carta Constitucional, dilucidar la necesidad de que la Administración Pública, basada en la defensa de la cultura y la historia nacional, busque actuar frente a este deber. proteger el patrimonio histórico-cultural nacional.

Palabras clave: Patrimonio; Preservación; Administración pública.

\section{Introdução}

Existem, em âmbito nacional, lugares que são considerados representativos de histórias e memórias, sendo necessária a preservação dos mesmos, como forma de valorizar aquilo que é comum a um povo, no tempo e no espaço. Segundo as concepções de Françoise Choay (2001), o patrimônio engloba três categorias diferentes, quais sejam: os elementos pertencentes à natureza, as questões relacionadas ao intelecto e as produções humanas.

Incontáveis são os patrimônios representativos de histórias e identidades, seja em âmbito nacional, estadual ou municipal. Nessa perspectiva, como forma de elucidar a importância da preservação do patrimônio histórico, bem como apontar de que modo a administração pública encara essa responsabilidade, realizar-se-á um estudo na cidade de Itaporanga, na Paraíba, em que foi selecionado o Monumento ao Cristo Redentor, a servir de parâmetro para o presente trabalho.

Conforme ensinamentos de Marconi e Lakatos (2003, p. 83), "o método é o conjunto das atividades sistemáticas e racionais que, com maior segurança e economia, permite alcançar o objetivo - conhecimentos válidos e verdadeiros -, traçando o caminho a ser seguido, detectando erros e auxiliando as decisões do cientista".

Assim, considerando que o método possui diversas classificações, o presente estudo tratar-se-á de pesquisa esteada na metodologia dedutiva, partindo de generalizações e de preceitos legais abrangentes, para o caso concreto, parte da classe que já se encontra na generalização. No que diz respeito à natureza da pesquisa, esta será qualitativa, buscando não só mensurar o tema, mas também descrevê-lo, tendo em vista que os "métodos qualitativos são aqueles nos quais é importante a interpretação por parte do pesquisador com suas opiniões sobre o fenômeno em estudo." (Pereira; Shitsuka; Parreira; Shitsuka, 2018, p. 67).

Ainda, tratar-se-á de uma pesquisa exploratória, no que concerne ao nível de profundidade, pois tem por escopo proporcionar uma maior familiaridade com o problema. Outrossim, quanto aos procedimentos utilizados para coleta de dados, se fará o uso das técnicas bibliográfica e documental, buscando explicar o problema em questão a partir das teorias já existentes que abordam sobre a temática.

Ao final, pretende-se verificar, a partir da análise do Monumento ao Cristo Redentor, situado na cidade de Itaporanga, na Paraíba, a necessidade da atuação da administração pública, em âmbito nacional, estadual e municipal, na busca pela proteção e preservação do patrimônio histórico, cultural, artístico e natural, como forma de assegurar as memórias e histórias enraizadas nesses bens.

\section{Resultados e Discussão}

Em primeiro momento, antes de abordar sobre a conceituação e características do patrimônio histórico e cultural, é importante compreender a relevância dos espaços como sendo "lugares de memória". Essa expressão carrega em si uma 
importância singular, pois representa aqueles espaços e lugares que, de alguma forma, representam a história e o passado de gerações. Esses lugares fazem parte da memória de uma sociedade, relativamente a um passado comum, contribuindo para que os membros dessa sociedade se sintam integrantes daquele espaço. (Tomaz, 2010)

É possível considerar que, ao apreciar um lugar que possui significados históricos, são rememoradas lembranças de um passado, fazendo com que o apreciador, a partir das sensações e sentimentos originados, reviva momentos e fatos ali vivenciados, os quais fundamentam e esclarecem a realidade presente em que está inserido o ser humano. Esses lugares de memória podem ser caracterizados como edificações e monumentos que, em razão de suas especificidades e características próprias, são capazes de ilustrar e rememorar a forma de vida daquela sociedade que, no passado, fez uso desses bens materiais. Cada monumento, cada edificação, carrega em si não somente aquilo que se fez necessário para sua construção, mas, principalmente, carregam um conjunto de significados e memórias de vivências que ali foram experimentadas.

Relativamente a essa questão, aborda Ecléa Bosi (1987, pp. 199-200) que: “[...] cada geração tem, de sua cidade, a memória de acontecimentos que são pontos de amarração de sua história"; e ainda acrescenta que: "As lembranças se apóiam nas pedras da cidade". Nesse sentido, percebe-se que as memórias dos indivíduos estão intrinsecamente ligadas às construções que representam um passado comum a todos.

Diante dessa relevância, para a humanidade, dos lugares representativos de memórias e histórias, é imprescindível a preservação do patrimônio histórico e cultural, como forma de consagrar e valorizar aquilo que é comum a uma sociedade, no tempo e no espaço. Pode-se considerar que o patrimônio cultural compreende três categorias distintas: a primeira categoria diz respeito aos elementos que pertencem ao meio ambiente; a segunda, refere-se às questões ligadas ao intelecto, englobando as técnicas, o conhecimento, o saber; a terceira categoria trata mais objetivamente do patrimônio histórico, abrangendo todas as coisas, artefatos e construções produzidos pelo homem a partir da sua relação com a natureza e do seu conhecimento, intentando garantir seu bem-estar. Françoise Choay, relativamente à conceituação do patrimônio histórico, aponta que:

[...] designa um bem destinado ao usufruto de uma comunidade que se ampliou a dimensões planetárias, constituído pela acumulação contínua de uma diversidade de objetos que se congregam por seu passado comum: obras e obrasprimas das belas artes e das artes aplicadas, trabalhos e produtos de todos os saberes dos seres humanos. (Choay, 2001, p. 11)

Para a autora, o patrimônio não deve ser visto como uma mera coleção de objetos, monumentos ou edificações. Compactua-se com esse ponto de vista, posto que o patrimônio representa a história de determinado grupo social, contribuindo para a conservação da memória representativa de vivências passadas, de importância ímpar para as vivências presentes e futuras.

No Brasil, incontáveis são os patrimônios que representam a história e a identidade do povo, seja a caráter nacional, estadual ou municipal. Assim, como forma de abordar acerca da importância da preservação do patrimônio histórico, bem como apontar de que modo a administração pública encara essa responsabilidade, foi realizado um estudo na cidade de Itaporanga, na Paraíba, em que foi selecionado um monumento histórico a servir de parâmetro para o presente trabalho.

Itaporanga é um município brasileiro do Estado da Paraíba, que polariza a região do Vale do Piancó. Uma das principais atrações turísticas do município é o monumento ao Cristo Rei, erguido pelo falecido Monsenhor José Sinfrônio de Assis Filho. Padre Zé, como era mais conhecido, nasceu em 24 de maio de 1924, no sítio Barroso, município de Cajazeiras-PB (Padre Zé Sinfrônio, 2019). Enquanto criança, teve uma infância caracterizada pela pobreza e trabalho na roça e carpintaria, junto ao seu pai. Logo que iniciou os seus estudos no Grupo Escolar Monsenhor Milanês, foi descoberto como uma criança cuja vocação era servir a Deus, no sacerdócio. E assim era a sua vontade.

Após longos anos de insistência, José, convicto da sua missão e predestinação ao serviço de Deus, demonstrou-se 
modelado nas morais do Evangelho e conseguiu ser levado, em 02 de fevereiro de 1939, para o Seminário Arquidiocesano da Paraíba em João Pessoa, em razão de suas vocações sacerdotais. No Seminário, concluiu os cursos de Filosofia e Teologia.

Em janeiro de 1955, foi designado vigário da Paróquia de Nossa Senhora da Conceição em Itaporanga-PB. Nessa época, Itaporanga era considerada uma das cidades mais violentas da Paraíba, devido às disputas por terra. Padre Zé ficou temeroso dessa violência que destruía as famílias itaporanguenses, como também se comoveu com a grande seca que assolava a população. No entanto, sabiamente entendia que mais brilhante que a luz da ciência só o fulgor da fé.

Diante dessa realidade catastrófica, Padre Zé realizou uma promessa, que se aquela situação de miserabilidade e violência acabasse, construiria um monumento ao Cristo, como há em sua cidade natal, Cajazeiras-PB. Algum tempo depois, Padre Zé e população notaram que a cidade tornou-se mais apaziguada, pacífica, em comparação com a situação drástica vivida anteriormente. Assim, cumprindo seu desejo e sua promessa, Padre Zé iniciou o processo de construção da estátua.

O Monumento ao Cristo Rei, cuja história remonta ao ano de 1955, quando da chegada de Padre Zé a Itaporanga, foi fruto da promessa realizada por esse Padre, em prol da paz e bem-estar da população itaporanguense. A estátua do Cristo Rei é localizada no alto da Serra do Cantinho, em Itaporanga, e tem uma altura de aproximadamente 30 metros. Foi construída pelo arquiteto Alexandre Azevedo de Lacerda, a partir do ano de 1985.

Para ser possível erguer a estátua, Padre Zé contou com o auxílio voluntário dos fiéis católicos da região, que auxiliavam diretamente na edificação, ou realizavam doações de valores ou alimentos a serem revertidos em quantia, com a finalidade de auxiliar na concretização desse sonho. O monumento ao Cristo Rei foi inaugurado em 26 de novembro de 2000, na festa de Cristo Rei.

O monumento ao Cristo Rei, em Itaporanga-PB, é reconhecido como patrimônio histórico municipal. Essa edificação representa a intensa luta e vigorosa fé de Padre Zé, que tanto batalhou para propagar os ensinamentos de Cristo, educar e preparar a juventude para a vida. Como resultado de suas incansáveis buscas, Padre Zé conseguiu, majestosamente, contribuir para a pacificação de Itaporanga, bem como para apagar a imagem negativa de cidade violenta, que ela detinha. Para isso, não precisou de armas bélicas, de força física, e nem de nenhum batalhão. Ele precisou e trabalhou apenas com a fé, com o amor e com a educação.

A estátua carrega em si as memórias e a história de evolução por qual passou Itaporanga, representando o emprenho de Padre Zé em formar cidadãos de bem, conscientes, pacíficos e preparados para a vida. Com sua incansável vontade de garantir o bem-estar social da população, Padre Zé também foi responsável pela construção do Colégio Diocesano Dom João da Mata, pela criação da gráfica Monsenhor José Sinfrônio, a Filarmônica Cônego Manoel Firmino, pela ampliação da Igreja Matriz, pela criação da casa do menor São Domingos Sávio, pela abertura do Hospital Distrital, e ainda conseguiu a energia elétrica e a telefonia para Itaporanga (Padre Zé Sinfrônio, 2019), entre tantas outras ações.

Todas essas memórias são representadas fisicamente pelo patrimônio histórico do monumento ao Cristo Rei. A partir do seu significado, gerações passadas, atuais e futuras, puderam, podem e poderão conhecer uma parte importantíssima da história de Itaporanga e tudo que a envolveu, preservando ainda a memória daquele que tanto lutou pelo bem, desenvolvimento e evolução da cidade e da população: Monsenhor José Sinfrônio de Assis Filho, Padre Zé.

Nesse sentindo, considerando a condição de patrimônio histórico municipal, dada sua relevância para com a história e identidade do local, surge a necessidade de preservação e conservação dessa herança que se materializa na forma de uma estátua. Acerca da preservação de bens patrimoniais, entende-se que sua finalidade é de:

[...] conservar traços da vida comum, quotidiana, e mostrar como vivia a sociedade em determinada época, pois o que tende a ser conservado sempre será o objeto considerado valioso, seja pelo valor do material de que é composto, seja por uma herança histórica ligada a uma personalidade ilustre e por isso mesmo dominadora. (Tomaz, 2010, p. 05) 
Sendo assim, a conservação de bens patrimoniais deve ter, também, por objeto, edificações e monumentos considerados importantes para uma sociedade, em razão do significado que eles apresentam, tendo por finalidade preservar a história e a memória atribuída ao bem. Ainda, no que diz respeito à preservação do patrimônio histórico, "tem-se em mente o produto elaborado por dada sociedade, para a qual determinado monumento tem significações relevantes, por ser parte de sua construção histórica." (Tomaz, 2010, p. 05) Nesse sentido, o que torna um bem munido de valor patrimonial são os significados que esse bem possui para determinada sociedade, justificando assim a necessidade de sua preservação.

É importante considerar, ainda, que, atualmente, a proteção e a necessidade de preservação abrangem tanto os patrimônios históricos, como também os culturais, artísticos (bens artísticos) e o patrimônio natural (bens naturais), alcançando assim as paisagens, tradições, arquiteturas, monumentos, construções, documentos, sítios arqueológicos, peculiaridades gastronômicas, expressões de arte, entre outros bens valorizados e reconhecidos pelo corpo social, seja em âmbito nacional, estadual, municipal, ou até internacional. (Tomaz, 2010)

No Brasil, a primeira noção jurídica de Patrimônio Histórico e Artístico Nacional ocorreu com a Constituição de 1934, por meio do seu art. 10, III, o qual determinava que: "Art. 10 - Compete concorrentemente à União e aos Estados: III proteger as belezas naturais e os monumentos de valor histórico ou artístico, podendo impedir a evasão de obras de arte." (Brasil, 1934) Tal determinação tinha por finalidade promover a responsabilização do poder público pela proteção dos bens de valor histórico ou artístico, em âmbito nacional.

Em 1937, a Lei n 378 também passou a regular a matéria, posto que instituiu a criação do SPHAN - Serviço do Patrimônio Histórico e Artístico Nacional, hoje IPHAN - Instituto do Patrimônio Histórico e Artístico Nacional (Rezende et al., 2015). Tal entidade tem por finalidade preservar e proteger os bens históricos e culturais do Brasil, garantindo a sua permanência, tal como determina o art. 46 da referida lei: "Fica creado o Serviço do Patrimonio Historico e Artístico Nacional, com a finalidade de promover, em todo o Paiz e de modo permanente, o tombamento, a conservação, o enriquecimento e o conhecimento do patrimonio historico e artístico nacional." (Brasil, 1937)

Essa regulação foi de grande valia, pois, a partir dela, as constituições brasileiras posteriores mantiveram a ideia, ratificando o espírito de proteção do patrimônio como um direito e dever do Estado e dos cidadãos.

A exemplo disso, tem-se a Constituição Federal de 1988 que, notadamente, assume uma postura de proteção ao patrimônio histórico, cultural, artístico e natural. Por meio do seu art. 23, III, IV, a Carta Magna atribui como competência comum da União, dos Estados, do Distrito Federal e dos Municípios:

III - proteger os documentos, as obras e outros bens de valor histórico, artístico e cultural, os monumentos, as paisagens naturais notáveis e os sítios arqueológicos;

IV - impedir a evasão, a destruição e a descaracterização de obras de arte e de outros bens de valor histórico, artístico ou cultural; (Brasil, 1988)

Posteriormente, ainda como forma de tutelar tais interesses, a Constituição Federal dispõe, em seu art. 24, VII, VIII, que Compete à União, aos Estados e ao Distrito Federal legislar concorrentemente sobre: "VII - proteção ao patrimônio histórico, cultural, artístico, turístico e paisagístico; VIII - responsabilidade por dano ao meio ambiente, ao consumidor, a bens e direitos de valor artístico, estético, histórico, turístico e paisagístico;" (Brasil, 1988)

Além disso, objetivando sanar eventuais dúvidas a respeito do que constitui patrimônio cultural a ser tutelado pelo ordenamento jurídico brasileiro, a Carta Suprema de 1988, por meio do seu art. 216, pontua que:

Art. 216. Constituem patrimônio cultural brasileiro os bens de natureza material e imaterial, tomados individualmente ou em conjunto, portadores de referência à identidade, à ação, à memória dos diferentes grupos formadores da sociedade brasileira, nos quais se incluem: 
I - as formas de expressão;

II - os modos de criar, fazer e viver;

III - as criações científicas, artísticas e tecnológicas;

IV - as obras, objetos, documentos, edificações e demais espaços destinados às manifestações artístico-culturais;

$\mathrm{V}$ - os conjuntos urbanos e sítios de valor histórico, paisagístico, artístico, arqueológico, paleontológico, ecológico e científico. (Brasil, 1988)

Ainda no mesmo dispositivo, torna-se evidente que a responsabilidade pela preservação e proteção das variadas espécies de patrimônio é responsabilidade não só do Poder Público, como também da própria comunidade. Nesse sentido, dispõe o $\S 1^{\circ}$, art. 216, CF/88: “O Poder Público, com a colaboração da comunidade, promoverá e protegerá o patrimônio cultural brasileiro, por meio de inventários, registros, vigilância, tombamento e desapropriação, e de outras formas de acautelamento e preservação.” (Brasil, 1988)

Essa disposição é de grande relevância, pois atribui à administração pública o dever de promover a proteção do patrimônio cultural brasileiro. As formas como a administração pública pode atuar para alcançar a finalidade pretendida, são diversas. Sendo assim, pode o Poder Público tutelar o patrimônio cultural brasileiro por meio de inventários, registros, vigilância, tombamento, desapropriação, além de outras formas de acautelamento necessárias à preservação. Nesse sentido, urge mencionar, em razão de suas singularidades, algumas considerações acerca do tombamento e da desapropriação.

Entende-se por tombamento, de acordo com a perspectiva de Maria Sylvia Zanella di Pietro (2002), como sendo o procedimento administrativo pelo qual o Poder Público restringe parcialmente o uso, gozo e disposição dos bens de qualquer natureza cuja preservação seja de interesse público, em razão do vínculo que estes possuem com fatos históricos memoráveis ou por seu valor bibliográfico, artístico, arqueológico ou etnológico, intentando garantir a permanência, preservação e a proteção desses bens. Isso se torna possível, pois, estando o bem tombado, não é autorizado realizar sobre ele qualquer intervenção que venha deturpar a sua originalidade, a exemplo da demolição ou reforma. Porém, os bens tombados podem ser objeto de restauração ou manutenção, desde que cumpridas as exigências legais, e suas características originais permaneçam intactas.

A competência para exercer o tombamento é da União, dos Estados e dos Municípios. Em âmbito federal, o órgão competente para concretizar o tombamento é o IPHAN (Instituto do Patrimônio Histórico e Artístico Nacional), autarquia federal cuja vinculação é com o Ministério da Cultura. Em âmbito estadual e municipal, a competência para tal ação é do órgão que porventura seja criado para exercer essa incumbência. (Schimitt, 2002?)

No que diz respeito à desapropriação, esta consiste em um procedimento pelo qual o Poder Público, embasado na necessidade pública, no interesse social ou na utilidade pública, de forma compulsória, retira do dono originário a propriedade em relação a certo bem, sendo este revertido e transformado em bem de caráter público (Di Pietro, 2002). A desapropriação deve ser realizada mediante justa e prévia indenização, conforme determina a Constituição Federal de 1988, em seu art. $5^{\circ}$, XXIV: "a lei estabelecerá o procedimento para desapropriação por necessidade ou utilidade pública, ou por interesse social, mediante justa e prévia indenização em dinheiro, ressalvados os casos previstos nesta Constituição;" (Brasil, 1988) A desapropriação é regulada pelo Decreto Lei no 3365/41, que consiste na lei geral da desapropriação no Brasil.

Ademais, cabe ainda pontuar que, por meio do seu art. 30, IX, a Constituição Federal de 1988 institui ainda que compete aos municípios "promover a proteção do patrimônio histórico-cultural local, observada a legislação e a ação fiscalizadora federal e estadual.” (Brasil, 1988).

Em âmbito estadual, a tutela ao patrimônio encontra-se presente na Constituição do Estado da Paraíba, posto que, em seu art. $2^{\circ}$, XIX, fica estabelecida, como um objetivo prioritário do Estado, a "proteção ao meio ambiente e ao patrimônio histórico, cultural e urbanístico;" (Brasil, 1989). Ainda na seara estadual, o monumento ao Cristo Rei, em Itaporanga, é considerado, pela Lei n ${ }^{\circ}$ 8.726/2008, uma das Sete Maravilhas do Estado da Paraíba (Brasil, 2008). Além disso, é por meio da 
Lei $\mathrm{n}^{\circ}$ 8.401/2007, também estadual, que a estátua é incluída no Roteiro Turístico do Estado da Paraíba (Brasil, 2007). Fica evidente, portanto, a relevância histórica e cultural do monumento ao Cristo Rei, bem como a necessidade da sua preservação e proteção.

No que diz respeito ao âmbito municipal, a Lei Orgânica do Município de Itaporanga ratifica a disposição do já mencionado art. 23, III, IV, da CF/88, elencando, em seu art. $8^{\circ}$, III, IV:

Art. $8^{\circ}$ - É da competência administrativa comum do Município, da União e do Estado, observado a lei complementar, o exercício das seguintes medidas:

III - proteger os documentos, as obras, e outros bens de valor histórico, artístico e cultural, os monumentos, as paisagens naturais e os sítios arqueológicos;

IV - impedir a evasão, a destruição e a descaracterização de obras de arte e de outros bens de valor histórico, artístico ou cultural; (Brasil, 1990)

Posteriormente, a Lei Orgânica do Município de Itaporanga, por meio do seu art. 133, II, ainda estabelece que "O Município promoverá o desenvolvimento cultural da comunidade local, nos termos da Constituição da República: II - proteção aos locais e objetos de interesse histórico, cultural e paisagístico;" (Brasil, 1990)

Portanto, diante de todas essas explanações de ordem legal e constitucional, pode-se concluir pela responsabilidade do Estado da Paraíba, do município de Itaporanga, como também da própria sociedade, em promover a preservação e proteção do seu patrimônio histórico e cultural, especialmente no que diz respeito ao monumento ao Cristo Redentor, objeto desse trabalho.

\section{Considerações Finais}

Diante do exposto, fica evidente, portanto, que qualquer deturpação ao patrimônio histórico e cultural da cidade de Itaporanga, especialmente no que diz respeito ao monumento ao Cristo Redentor, viola diretamente a Constituição Federal, a Constituição do Estado da Paraíba, as Leis Estaduais nº 8.401/07 e no 8.726/2008, bem como a Lei Orgânica do Município de Itaporanga.

Havendo, portanto, qualquer dano ou ameaça de dano à preservação do patrimônio, cabe à administração pública atuar em defesa da proteção aos locais, objetos, culturas, edificações, entre outros bens de interesse cultural, histórico, artístico ou natural, como forma de preservar a memória e a história de determinada localidade, ou de determinado grupo social. Como já pontuado anteriormente, o Poder Público pode atuar por meio inventários, registros, vigilância, tombamento, desapropriação, além de outras formas de acautelamento necessárias à preservação, permanência e proteção do patrimônio.

Assim, evidencia-se a importância e necessidade da atuação da administração pública, em âmbito nacional, estadual e municipal, na busca pela proteção e preservação do patrimônio histórico, cultural, artístico e natural. Portanto, como forma de fomentar essa necessidade, acreditamos que investigações como esta devem ser prosseguidas. Sendo assim, como sugestão para continuidade de discussões nesse sentido, averiguar, à luz dos ditames de proteção ao patrimônio histórico, cultural, artístico e natural, o contraponto existente entre estes direitos e o atual cenário brasileiro no que diz respeito à tutela patrimonial, contribuirá para o fortalecimento e planejamento de estratégias capazes de assegurar as memórias e histórias enraizadas nesses bens, estas que integram e são relevantes a determinado grupo social.

\section{Referências}

Bosi, E. (1987). Memória da cidade: lembranças paulistanas. Instituto de Estudos Avançados. 1(1), 199-200.

Brasil, Constituição (1989). Constituição do Estado da Paraíba: promulgada em 5 de outubro de 1989. http://www.al.pb.leg.br/wpcontent/uploads/2017/02/Constitui\%C3\%A7\%C3\%A3o-Estadual-Atualizada-at\%C3\%A9-a-Emenda-40-de-2015.pdf. 
Research, Society and Development, v. 10, n. 3, e54010313671, 2021

(CC BY 4.0) | ISSN 2525-3409 | DOI: http://dx.doi.org/10.33448/rsd-v10i3.13671

Brasil. Lei Orgânica do Município de Itaporanga (1990): promulgada em 05 de abril de 1990 . http://itaporanga.pb.gov.br/images/arquivos/documentos/1403359049.pdf.

Brasil. Constituição (1934). Constituição da República dos Estados Unidos do Brasil: promulgada em 16 de julho de 1934. http://www.planalto.gov.br/ccivil_03/constituicao/constituicao34.htm.

Brasil. Constituição (1988). Constituição da República Federativa do Brasil de 1988: promulgada em 5 de outubro de 1988. http://www.planalto.gov.br/ccivil_03/constituicao/constituicao.htm.

Brasil. Lei no . 378, de 13 de janeiro de 1937. Dá nova organização ao Ministério da Educação e Saúde Pública. Capital Federal, 1937.

Brasil. Lei 8.401, de 27 de novembro de 2007. Inclui, no Roteiro Turístico do Estado da Paraíba, o Cristo Redentor de Itaporanga. Diário Oficial do Estado, João Pessoa, 27 nov. 2007.

Brasil. Lei 8.726, de 23 de dezembro de 2008. Define as Sete Maravilhas dos principais pontos turísticos da Paraíba e dá outras providências. Diário Oficial do Estado, João Pessoa, 23 dez. 2008.

Choay, F. (2001). A alegoria do patrimônio. Unesp, p.11. UFSM.

Di Pietro, M. S. Z. (2002). Direito Administrativo. (14a ed.), Atlas.

Marconi, M. A. \& Lakatos, E. M. (2003). Fundamentos de Metodologia Científica (5a ed.). Atlas.

Padre Zé Sinfrônio. (2019) Coisas de Cajazeiras. https://coisasdecajazeiras.com.br/almanaque/padre-ze-sinfronio/.

Paulo: Atlas.

Pereira, A. S., Shitsuka, D. M., Parreira F. J., \& Shitsuka R. (2018). Metodologia da Pesquisa Científica UFSM.

Rezende, M. B. et. al. (2015). Serviço do Patrimônio Histórico e Artístico Nacional - SPHAN. In Rezende, M. B. et. al. (Orgs.). Dicionário IPHAN de Patrimônio Cultural. Rio de Janeiro, Brasília: IPHAN/DAF/Copedoc. (verbete).

Schimitt, F. (2002?). Tombamento: Proteção do Patrimônio Histórico e Artístico Nacional à Luz da Constituição Federal, Dec.-Lei n. 25 de 30/11/37 e Lei n. 3.924de20/07/61.sedep.com. https://www.sedep.com.br/artigos/tombamento-protecao-do-patrimonio-historico-e-artistico-nacional-a-luz-da-constituicaofederal/

Tomaz, P. C. (2010). A preservação do patrimônio cultural e sua trajetória no Brasil. Revista de História e Estudos Culturais, 7(2). www.revistafenix.pro.br. 